\title{
Prevalence of and factors associated with benzodiazepine use in community-resident elderly persons
}

Abstract

Objective: to assess the prevalence of and factors associated with the use of benzodiazepines in elderly persons living in the community. Method: a cross-sectional study was conducted through a household survey of 423 elderly persons from Juiz de Fora, Minas Gerais, Brazil. To analyze the factors associated with the outcome, the Poisson regression model was used, based on the theoretical model of determination with hierarchical blocks. The variables were adjusted within each block, with those with a 5\% significance level remaining in the final model. Result: The prevalence of benzodiazepine use was $18.3 \%$ (95\% CI 15.2 to 21.6). Most benzodiazepines used had a long-elimination half-life (59.2\%) and use was considered long in $85.5 \%$ of users. Among benzodiazepine users $38.4 \%$ also used antidepressants. The use of these drugs was associated with the presence of selfreported mental and behavioral disorders, polypharmacy and medical visits in the last three months. Conclusion: The use of benzodiazepines was considered high among the elderly. The reduction in the prescription of these drugs should be assessed individually, considering the physiological alterations of the elderly and the adverse effects of drugs, in order to minimize incorrect prescriptions.

\footnotetext{
Universidade Federal de Juiz de Fora. Programa de pós graduação em Saúde Coletiva. Juiz de Fora, MG, Brasil.

2 Universidade Federal de Juiz de Fora. Departamento de Saúde Coletiva. Juiz de Fora, MG, Brasil.

3 Universidade Federal de Juiz de Fora. Departamento de Estatística. Juiz de Fora, MG, Brasil.
}

Research Funding: Conselho Nacional de Desenvolvimento Científico e Tecnológico (the National Council for Scientific and Technological Development) (CNPq) and Ministério da Ciência e Tecnologia (the Ministry of Science and Technology) (MCT), No. 480163 / 2012-0

Mariana Macedo Alvim?

Danielle Teles da Cruz ${ }^{2}$

Marcel de Toledo Vieira ${ }^{3}$

Ronaldo Rocha Bastos ${ }^{3}$

Isabel Cristina Gonçalves Leite ${ }^{2}$

Keywords: Aging. Health of the Elderly. Cross-Sectional Studies. Benzodiazepines. 


\section{INTRODUCTION}

Greater susceptibility to chronic diseases, disabilities, psychosocial problems and comorbidities are more prevalent in old age. The process of population has brought about a growing concern about mental health care, mainly due to the high prevalence of mental disorders in the elderly population, particularly mood and anxiety disorders ${ }^{1}$.

The use of medication is one of the main forms of treatment for the control and prevention of the most prevalent chronic health conditions, especially in the case of the elderly. The elevated use of drugs makes this population more susceptible to the risks of polypharmacy and problems related to pharmacotherapy ${ }^{2}$.

Among the medications used by the elderly, the chronic use of psychotropic drugs, especially benzodiazepine class hypnotics, sedatives and anxiolytics, is highlighted, due to the constant insomnia and anxiety that affect this group. Chronic use of psychoactive drugs can lead to serious consequences, such as increased drug interactions, adverse reactions, and the development of dependence and tolerance. The elevated consumption of drugs, especially of psychoactive drugs, may be related to the reduction of functional capacity and consequently a low quality of life ${ }^{3}$.

The evelated use of psychotropic drugs emphasizes the need for intervention ${ }^{4}$. Benzodiazepines are highly prominent among psychotropic drugs, and their popularization has revealed new problems, mainly due to inadequate use. Chemical dependence on benzodiazepines with all the inherent implications of such conditions has become a major concern for public health.

The prolonged use of benzodiazepines is associated with many adverse effects, including sedation, amnesia, cognitive impairment and ataxia, in addition to a greater number of falls 5 . Such drugs also add to the development of psychological dependence in chronic benzodiazepine users, and both physicians and patients have difficulty implementing protocols to reduce their use. Many patients deny or minimize side effects, or express a reluctance to risk suffering without the drug ${ }^{6}$.
It is essential to understand the patterns of medication use by the elderly population, in order to establish ways to ensure their rational use, the improvement in quality of life and the maintenance of functional capacity. Given the above, the present study aims to evaluate the prevalence of benzodiazepine use in the elderly and associated factors.

\section{METHOD}

The present study originates from an observational follow-up study of elderly residents in the northern zone of the city of Juiz de Fora, Minas Gerais, Brazil. The present study is part of the second cross-sectional phase. The northern zone is the region of the city with the greatest territorial availability in the urban area and has the second largest population in the municipality, as well as having the largest number of neighborhoods, concentration of unplanned communities and social programs?.

Data were obtained through two household surveys conducted in 2010 and 2014-2015. The individuals were selected by conglomerate sampling, and the primary sampling subunits were the census tracts. As the current survey has multiple outcomes, the sample size was calculated based on a prevalence of $50 \%$, deff 1.5 (considering stratification effect and cluster) and a significance level of $95 \%$.

All the elderly participants of the first survey (2010) were visited again. Losses over time included a change of address where it was not possible to obtain the new address, where the elderly person was not found after three attempts at contact at different times and on different days, and refusals. The losses were not differential. To compensate for losses, the oversample ${ }^{8}$ method was used, considering cluster sampling. Thus, 248 elderly people included in the 2010 sample participated in the present study, in addition to 175 new elderly people, and the study was composed of 423 individuals.

The questionnaire used was standardized and previously tested. Data collection was performed at the homes of the elderly persons between September 2014 and March 2015. Quality control of the information collected was performed, in which $10 \%$ of the sample was evaluated by a new partial 
interview. The Mini Mental State Exam (MMSE) was used to screen for cognitive impairment ${ }^{9}$. Elderly persons who did not reach the minimum established for the study ${ }^{10}$ had their questionnaires answered by a caregiver/family member. In such cases, selfperception questions were not answered. In the absence of another respondent, the elderly were excluded from the study.

The dependent variable was the continuous use of benzodiazepines. The independent variables were selected based on theoretical reference ${ }^{11-14}$ and were grouped into three blocks. The first block included the sociodemographic variables (distal determinants), which are responsible for conditioning the variables of the other blocks. The second block (intermediate determinants) included variables related to the health of the elderly. Variables relating to health services were allocated in the third block.

The variables of each block included: Block 1) sociodemographic variables: gender; age; schooling; ethnicity (white, black, yellow (Asian-Brazilian), brown (mixed-race), indigenous); marital status (single, married/stable, widowed, separated/divorced, other); home arrangement (lived alone or with others); Block 2) variables related to the health of the elderly: perception of health, vision and hearing (excellent, very good, good, fair and poor); selfreported comorbidities (classified according to the International Classification of Diseases - ICD 10), including diseases of the nervous system, mental and behavioral disorders; frailty measured according to the Edmonton scale ${ }^{15}$ (does not present frailty, apparently vulnerable, mild frailty, moderate frailty and severe frailty); functional capacity for the performance of instrumental activities of daily living (IADL) classified by the Lawton-Brody scale ${ }^{16}$ (dependence, partial dependence and independence); suggestion of anxiety and/or depression, according to the Patient Health Questionnaire (PHQ-4) scale ${ }^{17}$; falls in the last year (yes or no); continuous-use medication (yes or no); polypharmacy ${ }^{18}$ (yes or no); Block 3) variables related to the health service: type of coverage of the public health service [discovery area, Basic Health Unit (BHU) with Family Health Strategy, traditional $\mathrm{BHU}]$; possesses a health plan (yes or no); satisfaction with medical health service (yes or no), including public and private services; medical consultation in the last three months (yes or no).

In order to evaluate the use of medicines, the question used was: "Do you continuously use any medication?" If so, the boxes or blister packs of the medication were analyzed. In the absence of these, the information was completed according to the reports of the elderly. The study considered polypharmacy to be the use of five or more drugs ${ }^{18}$. Benzodiazepines were classified according to their elimination half-life ${ }^{19}$ : short/intermediate acting (half-life up to 24 hours) and long-acting (half-life greater than 24 hours). The time of continuous treatment with benzodiazepines was stratified as up to six months of treatment or greater than six months, the second case being considered as a prolonged period $^{20}$.

Initially the data were submitted to descriptive univariate analysis to obtain the absolute and relative frequency of the variables analyzed, as well as the prevalence of the investigated variable. For the quantitative variables, measures of central tendency and dispersion were calculated. The chisquare test was used in the bivariate analysis to verify the association between each of the independent variables and the dependent variable.

Multivariate analysis was based on the proposed theoretical model of determination with hierarchical blocks of variables (Figure 1) to control for possible confounding factors. Initial adjustment was performed within each block, with variables with a level of significance less than or equal to 0.20 in the bivariate analysis included. The variables that achieved a score of $p<0.05$ in the block analysis were maintained in the final model, with those that retained a significance level of $5 \%(p<0.05)$, controlled by all the significant variables of the blocks immediately above, included in this model. For the multivariate analysis, the Poisson regression model was used to estimate crude and adjusted prevalence ratios, with a robust estimate of variance and a 95\% confidence interval $(95 \% \mathrm{CI})$. 


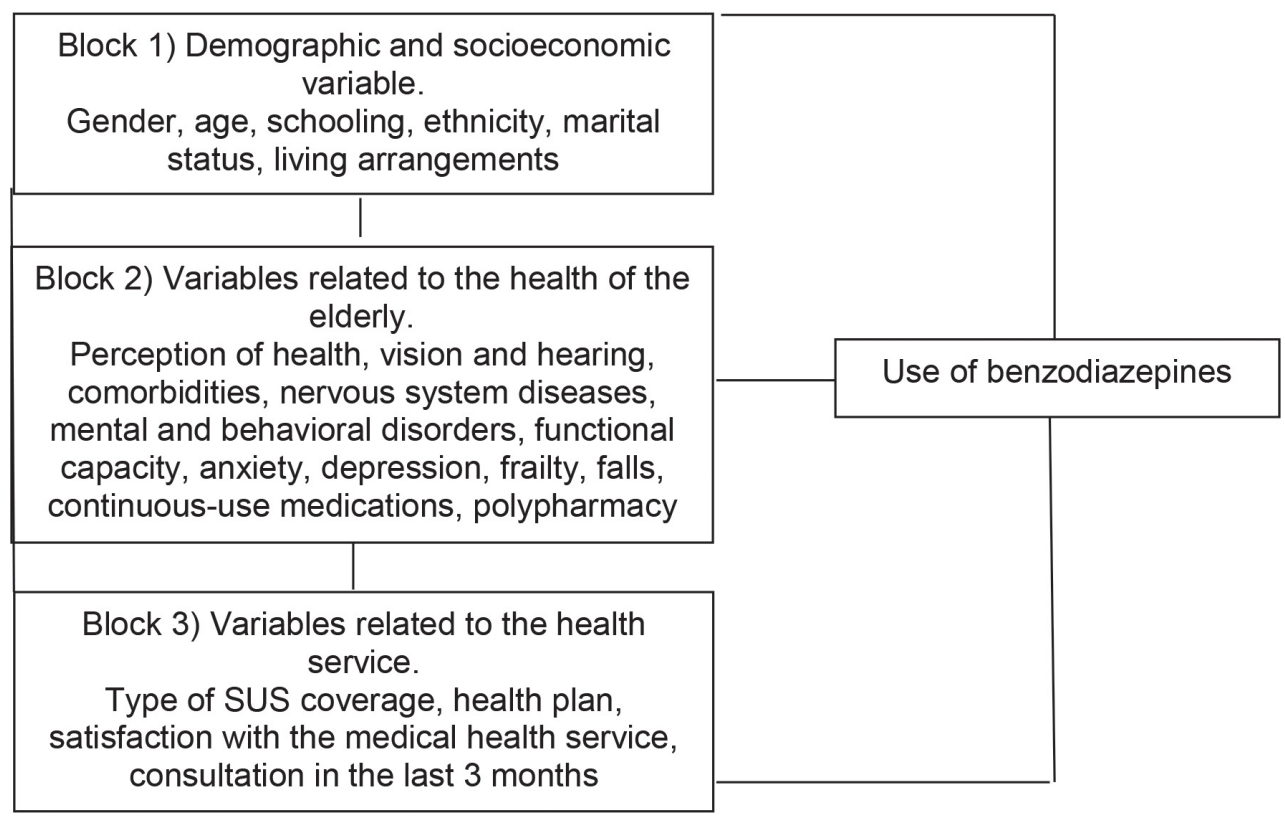

Figure 1. Theoretical model of investigation of the effects of the independent variables on the use of benzodiazepine in hierarchical blocks. Juiz de Fora, MG, 2015.

The study was approved by the Ethics Research Committee of the Universidade Federal de Juiz de Fora (Juiz de Fora Federal University), under approval n. 771.916, and a Free and Informed Consent Form was signed by all the participants.

\section{RESULTS}

A total of 423 questionnaires were analyzed, of which 23 were excluded due to poor MMSE performance and the lack of another respondent. The final sample consisted of 400 elderly individuals, with 315 (78.8\%) questionnaires answered by the elderly themselves and $85(21.2 \%)$ by another respondent.

The majority of the participants were women $(64.5 \%)$, lived with another person $(89.5 \%)$, were married or in a common-law marriage (55.8\%), and declared themselves as white (45.5\%). The mean age was 73.8 years $( \pm 8.0)$ and mean schooling was 4.2 years $( \pm 3.4)$.
A poor or fair health perception was reported by $43.5 \%$ of the elderly, $54.9 \%$ described having fair or poor vision, and $28.6 \%$ had fair or poor hearing. The presence of comorbidities was reported by $89.0 \%$ of the elderly persons, and $4.8 \%$ reported diseases of the nervous system and $11.3 \%$ mental and behavioral disorders. Most were independent in the assessment of functional capacity for instrumental activities of daily living (Lawton and Brody Scale, 84.5\%) and presented some level of frailty (Edmonton Scale, $57.8 \%$ ). A suggestion of anxiety was verified in $72.7 \%$ of the elderly and there was a suggestion of depression in $77.1 \%$ (PHQ-4 Scale).

In terms of health services, the majority of the elderly resided in an area that had BHU care within the Family Health Strategy (74.0\%) and 60.3\% had a health plan. Of the elderly who used medical health services, $81.3 \%$ were satisfied with the service. The prevalence of a medical consultation in the last three months was $76.0 \%$. The characteristics of the sample according to the independent variables are described in Table 01. 
Table 1. Characteristics of the sample according to the use of benzodiazepines. Juiz de Fora, Minas Gerais, 2015.

\begin{tabular}{|c|c|c|}
\hline \multirow{2}{*}{ Variables } & \multicolumn{2}{|c|}{ Use of benzodiazepines } \\
\hline & Yes. n $(\%)$ & No. $\mathrm{n}(\%)$ \\
\hline \multicolumn{3}{|l|}{ Sociodemographic variable } \\
\hline \multicolumn{3}{|l|}{ Gender } \\
\hline Male & $19(26.0)$ & $123(37.6)$ \\
\hline Female & $54(74.0)$ & $204(62.4)$ \\
\hline \multicolumn{3}{|l|}{ Age (years) } \\
\hline $60-69$ & $25(34.2)$ & $111(33.9)$ \\
\hline $70-79$ & $33(45.2)$ & $132(40.4)$ \\
\hline 80 or more & $15(20.5)$ & $84(25.7)$ \\
\hline \multicolumn{3}{|c|}{ Variables related to the health of the elderly person } \\
\hline \multicolumn{3}{|l|}{ Comorbidities } \\
\hline Presence & $68(93.2)$ & $288(88.1)$ \\
\hline Absence & $5(6.8)$ & $39(11.9)$ \\
\hline \multicolumn{3}{|l|}{ Nervous system diseases* } \\
\hline Yes & $8(11.8)$ & $9(3.1)$ \\
\hline No & $60(88.2)$ & $278(96.9)$ \\
\hline \multicolumn{3}{|l|}{ Mental and behavioral disorders* } \\
\hline Yes & $18(26.5)$ & $22(7.7)$ \\
\hline No & $50(73.5)$ & $265(92.3)$ \\
\hline \multicolumn{3}{|c|}{ Functional Capacity for the performance of IADL } \\
\hline Independent & $62(84.9)$ & $276(84.4)$ \\
\hline Partial Dependency to Dependency & $11(15.1)$ & $51(15.5)$ \\
\hline \multicolumn{3}{|l|}{ Suggestion of Anxiety* } \\
\hline No & $34(58.6)$ & $195(75.9)$ \\
\hline Yes & $24(41.4)$ & $62(24.1)$ \\
\hline \multicolumn{3}{|l|}{ Suggestion of Depression* } \\
\hline No & $39(67.2)$ & $204(79.4)$ \\
\hline Yes & $19(32.8)$ & $53(20.6)$ \\
\hline \multicolumn{3}{|l|}{ Frailty* } \\
\hline Did not exhibit frailty & $16(27.6)$ & $127(45.2)$ \\
\hline Apparently vulnerable & $10(17.2)$ & $65(23.1)$ \\
\hline Mild frailty & $13(22.4)$ & $51(18.1)$ \\
\hline Moderate to severe frailty & $19(32.7)$ & $38(13.5)$ \\
\hline \multicolumn{3}{|l|}{ Falls in last year } \\
\hline Yes & $27(37.0)$ & $114(34.9)$ \\
\hline No & $46(63.0)$ & $213(65.1)$ \\
\hline \multicolumn{3}{|l|}{ Polypharmacy* } \\
\hline Yes & $51(69.9)$ & $127(43.1)$ \\
\hline No & $22(30.1)$ & $168(56.9)$ \\
\hline \multicolumn{3}{|l|}{ Variables related to health service } \\
\hline \multicolumn{3}{|l|}{ Satisified with health service* } \\
\hline Yes & $63(86.3)$ & $258(80.1)$ \\
\hline No & $10(13.7)$ & $64(19.9)$ \\
\hline \multicolumn{3}{|c|}{ Medical consultation in last three months } \\
\hline Yes & $66(90.4)$ & $238(72.8)$ \\
\hline No & $7(9.6)$ & $89(27.2)$ \\
\hline
\end{tabular}

IADL: instrumental activities of daily living; *Excluding non-respondents. 
In terms of pharmacological therapy, $92.0 \%$ of the elderly used at least one continuous-use drug. Of these, $48.4 \%$ used five or more drugs, characterized as polypharmacy. The average number of medications used by the elderly was $4.8( \pm 2.9)$.

The prevalence of benzodiazepine use in the population was $18.3 \%$ (95\% CI 15.2-21.6) (73/400), with clonazepam, bromazepam and alprazolam being the most commonly used benzodiazepines. In addition, $4.1 \%(3 / 73)$ of the elderly used two benzodiazepines. Most of the benzodiazepines used by the elderly in the present study had a long elimination half-life (half-life greater than 24 hours, $59.2 \%$ ). The time of benzodiazepine use was greater than six months in $85.5 \%$ of users. Among the benzodiazepine users, $38.4 \%$ also used antidepressants. The characterization of the use of benzodiazepines by the elderly is described in Table 2 .
The variables that remained associated with the use of benzodiazepines in the bivariate analysis and the adjusted prevalence ratios within each hierarchical block are described in Table 3. In blockadjusted multivariate analysis, no block 1 variable was statistically significant $(p<0.05)$. In block 2 , the variables auditory perception, self-report of mental and behavioral disorders and polypharmacy were significant. The only significant variable in block 3 was medical consultation in the last three months.

After multiple regression analysis, three variables associated with the use of benzodiazepines remained in the final model (Table 4): presence of self-reported mental and behavioral disorders (adjusted PR $=4.72$, 95\%CI, 1.88-11.82), polypharmacy (adjusted PR $=2.17,95 \% \mathrm{CI}, 1.14-4.35)$ and medical consultation in the last three months (adjusted PR $=6.64,95 \% \mathrm{CI}$ 1.51-29.22).

Table 2. Characterization of benzodiazepine use by the elderly. Juiz de Fora, Minas Gerais, 2015.

\begin{tabular}{ll}
\hline Variables & $\mathrm{N}(\%)$ \\
\hline Use benzodiazepines & $73(18.3)$ \\
Yes & $327(81.2)$ \\
No & \\
\hline Active principle & $12 / 76(15.8)$ \\
Alprazolam & $15 / 76(19.7)$ \\
Bromazepam & $32 / 76(42.1)$ \\
Clonazepam & $2 / 76(2.6)$ \\
Cloxazolam & $9 / 76(11.8)$ \\
Diazepam & $2 / 76(2.6)$ \\
Flunitrazepam & $4 / 76(5.3)$ \\
Lorazepam & \\
\hline Elimination Half Life & $31 / 76(40.8)$ \\
Short/Intermediate & $45 / 76(59.2)$ \\
Long & \\
\hline Time of use (months)* & $9 / 62(14.5)$ \\
Up to 6 & $53 / 62(85.5)$ \\
Over 6 &
\end{tabular}

*Variable investigated only when respondent was the elderly person themselves. 
Table 3. Use of benzodiazepines according to independent variables. Juiz de Fora, Minas Gerais, 2015.

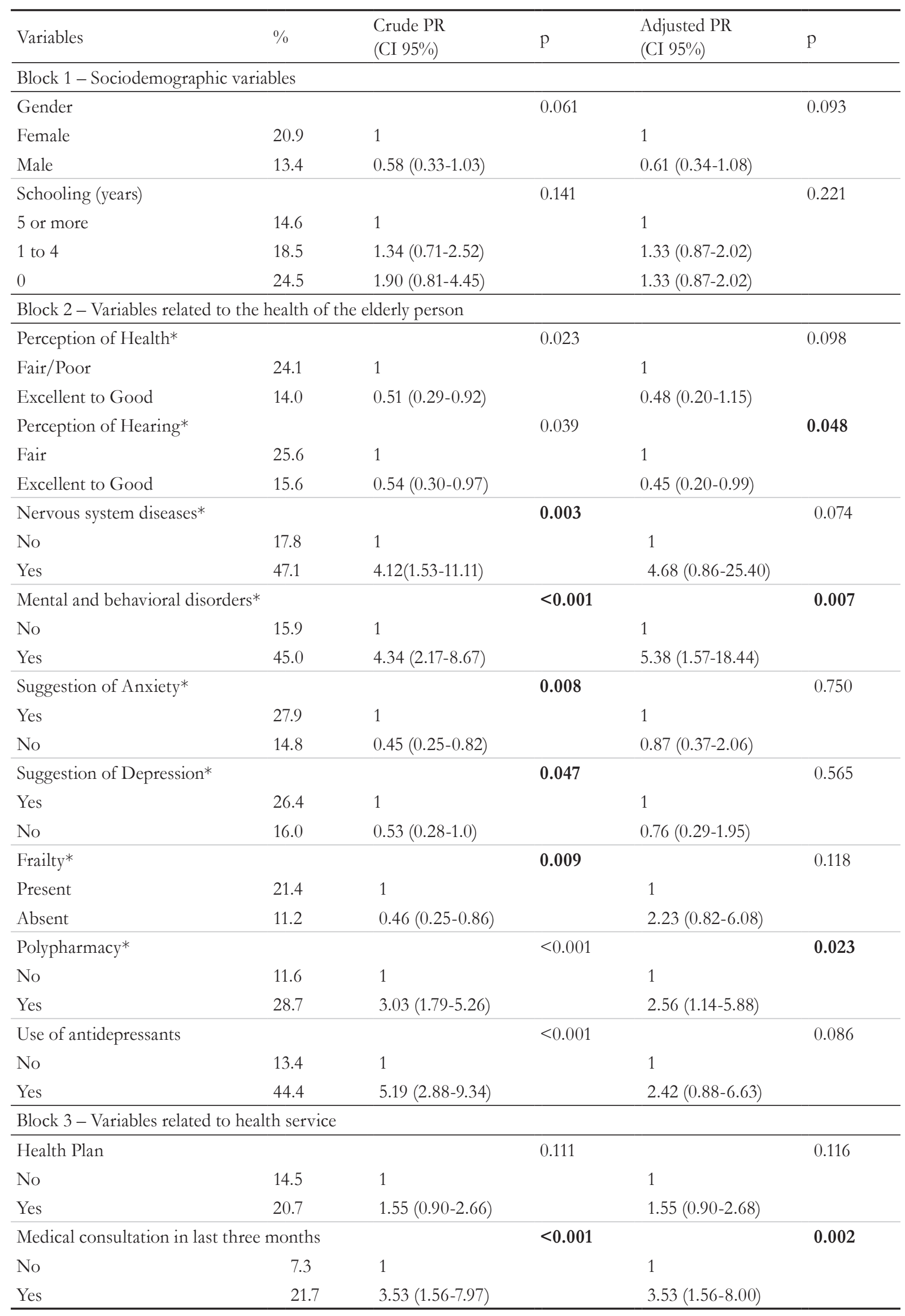

*Excluding non-respondents. 
Table 4. Final regression model of association of benzodiazepine use and independent variables. Juiz de Fora, Minas Gerais, 2015.

\begin{tabular}{|c|c|c|c|c|}
\hline Variables & $\begin{array}{l}\text { Crude PR } \\
(\mathrm{CI} 95 \%)\end{array}$ & $\mathrm{p}$ & $\begin{array}{l}\text { Adjusted PR } \\
\text { (CI 95\%) }\end{array}$ & $\mathrm{p}$ \\
\hline Mental and behavioral disorders* & & 0.007 & & 0.001 \\
\hline No & 1 & & 1 & \\
\hline Yes & $5.38(1.57-18.44)$ & & $4.72(1.88-11.82)$ & \\
\hline Polypharmacy* & & 0.023 & & 0.020 \\
\hline No & 1 & & 1 & \\
\hline Yes & $2.56(1.14-5.88)$ & & $2.17(1.14-4.35)$ & \\
\hline Medical consultation in last three months & & 0.002 & & 0.012 \\
\hline No & 1 & & 1 & \\
\hline Yes & $3.53(1.56-8.00)$ & & $6.64(1.51-29.22)$ & \\
\hline
\end{tabular}

*Excluding non-respondents.

\section{DISCUSSION}

The prevalence of benzodiazepine use in the study population was $18.3 \%$, similar to that found in other studies $^{11,12}$. Prevalences that differ from the present study have also been reported in literature ${ }^{13,14,21}$. Differences between studies can be explained by the difference in definitions of use and the period of observation. The present study analyzed drugs in continuous use at the time of the interview, while others evaluated medication use in the 15 days, 90 days or 12 months prior to the interview. The contrasts identified may also reveal important differences among the analyzed populations, such as health service use, epidemiological profile, sociocultural characteristics, or even reflect the habits of those prescribing the drugs, in addition to the criteria used to indicate these medications ${ }^{14}$.

The high consumption of benzodiazepines may be related to the progressive decrease in humanity's resistance to stress, the introduction of new drugs, the increasing pressure of advertising by the pharmaceutical industry, or inadequate prescription habits on the part of professionals ${ }^{22}$. It should also be added that drugs are considered one of the main contemporary technologies of care, and promise to ward off any suffering caused by society, such as depression, anxiety, psychotic disorders, loneliness, economic crises and sadness, simply through the administration of an effective chemical in the body ${ }^{4}$.
The long-term use of benzodiazepines in 85.5\% of the elderly and the high prevalence of long half-life benzodiazepines $(59.2 \%)$ are noteworthy. Long-acting benzodiazepines accumulate when taken repeatedly and their undesirable effects may manifest themselves after several days or weeks ${ }^{23}$. According to the Beers-Fick and STOPP criteria for drugs that are inappropriate for the elderly, the use of benzodiazepines should be avoided in such individuals, regardless of the half-life of the drug ${ }^{24,25}$.

Restrictions on the use of benzodiazepines by the elderly have been increasing, related to depression of the central nervous system, such as decreased psychomotor activity, memory impairment and the potentiation of the depressive effect through interaction with other depressant drugs ${ }^{22}$. Literature indicates that even short-acting benzodiazepines are a significant risk factor for the frequency of falls in geriatric patients ${ }^{26}$.

A prospective study by Billioti de Gage et al. ${ }^{27}$ showed that the use of benzodiazepines is associated with an increased risk of dementia. The risk of dementia increases with cumulative dose, duration of treatment, and when long-acting drugs are used ${ }^{27}$. Specific concerns about prolonged use also include the development of tolerance and increased dosage, addiction, drug abuse and difficulty of withdrawa ${ }^{5,6}$. Drug dependence leads to the annulment of responses to social suffering related to gender, aging and poor 
economic and quality of life conditions, promoting psychiatric illnesses such as anxiety and depression, which can be intensified in the elderly and stimulated by the continuous use of medications ${ }^{28}$.

The difficulty of withdrawing benzodiazepine use from patients who have become dependent due to prolonged use is also an important issue. Modifying consumption in patients who have used benzodiazepines for several years remains a challenge. The reason for the continued use of benzodiazepines is described as a fear of the return and intensification of symptoms, or impairment of the performance of daily activities. Psychological dependence and the underestimation or negation of the potential side effects of benzodiazepines contribute to the resistance, especially of the elderly, to discontinuing medication ${ }^{29}$.

Factors associated with the use of benzodiazepines found in the present study following multivariate analysis were the presence of mental and behavioral disorders, polypharmacy and a medical consultation in the last three months. An association between the use of benzodiazepines and mental and behavioral disorders was verified in other studies, with use associated with common mental disorders ${ }^{11}$ and previous psychiatric illnesses ${ }^{20}$.

The association between the use of benzodiazepines and the use of other drugs has been verified in literature ${ }^{11}$. In the present study the use of benzodiazepines was associated with polypharmacy. The presence of comorbidities and consultation with different specialists may be related to this practice ${ }^{14}$. Polypharmacy does not necessarily indicate that the prescription and use of the drugs is incorrect, and it is often necessary to guarantee a better quality of life for the elderly person ${ }^{30}$. However, the number of drugs prescribed, the complexity of therapeutic regimens, especially in the case of comorbidities, and the pharmacokinetic and pharmacodynamic changes inherent in the aging process, increase the vulnerability of the elderly to medications, whether due to adverse reactions, drug interactions or side effects $^{31}$. In a study by Richardson et al. ${ }^{5}$, it was found that the use of benzodiazepines was associated with an increased risk of falls when combined with polypharmacy.
The periodic medical consultations by users of benzodiazepines may be justified by the fact that these drugs are only dispensed with a medical prescription, and the amount dispensed is only sufficient for a maximum of 60 days of treatment. Studies have confirmed this association ${ }^{11,12}$. Contact with the medical service is seen as an opportunity to obtain the prescription of a psychotropic drug ${ }^{12}$. On the other hand, the use of benzodiazepines may increase the patient's contact with the physician. According to Auchewski et al. $^{22}$, a return visit to the doctor may be interpreted as the desire of the prescriber to accompany the response of the patient to the benzodiazepines, including dose monitoring, evaluation of side effects and therapeutic response. A return visit to the doctor should be seen as a precaution, as a rational prescription should be based on the continuous monitoring of the patient. However, in practice, it has been observed that patients only return to obtain a new prescription. A study carried out by Alvarenga et al. ${ }^{32}$ reports the ease of the acquisition of prescriptions, which can be obtained without the need for a formal medical consultation or adequate medical guidance on the care needed during treatment. A link is not established with the medical professional or with the health service, but with the medication itself, with the need to present a prescription being understood as an obstacle.

The use of benzodiazepines in geriatrics should be carried out with discretion and according to specific criteria, since the sensitivity of the elderly to benzodiazepines and their half-life increases considerably with age. Despite the growing concern, the use of benzodiazepines by the elderly remains high. This is largely because no superior pharmacotherapeutic alternative has been developed to treat anxiety and insomnia. Benzodiazepines act fast and, at least in the initial prescription stage, are safe and possess predictable effects ${ }^{33}$.

Reducing the prescription of benzodiazepines requires replacement with other treatments for sleep disorders and anxiety, many of which are non-pharmacological ${ }^{12}$. Gradual cessation of use may be effective, with a gradual reduction in dose. Cognitive behavioral therapy is considered effective for the treatment of chronic insomnia, facilitating 
the reduction of the use of benzodiazepines in the elderly ${ }^{34}$. Interventions in the areas of prescription, substitution, psychotherapies and pharmacotherapies may contribute to the management of benzodiazepine dependence. Efforts should be made to educate and support patients. In addition, proper interaction between medical professionals and patients may contribute to tackling the problem of inappropriate prescriptions.

Consideration should be given to the limitations of the present study, mainly due to its cross-sectional design, which does not allow the evaluation of temporal relationships, as well as the impossibility of identifying the therapeutic indication of the drug, the existence of adverse events and the occurrence of drug interactions. The advantages of the study

\section{REFERENCES}

1. Byrne GJ, Pachana NA. Anxiety and depression in the elderly: do we know any more? Curr Opin Psychiatr. 2010;23(6):504-9.

2. Guimarães VG, Brito GC, Barbosa LM, Aguiar PM, Balisa-Rocha BJ, Lyra Júnior DP. Perfil farmacoterapêutico de um grupo de idosos assistidos por um programa de Atenção Farmacêutica na Farmácia Popular do Brasil no município de Aracaju SE. Rev Ciênc Farm Básica Apl. 2012;33(2):307-12.

3. Oliveira MPF, Novaes MRCG. Perfil socioeconômico, epidemiológico e farmacoterapêutico de idosos institucionalizados de Brasília, Brasil. Ciênc Saúde Coletiva. 2013;18(4):1069-78.

4. Netto MUQ, Freitas O, Pereira LRL. Antidepressivos e benzodiazepínicos: estudo sobre o uso racional entre usuários do SUS em Ribeirão Preto-SP. Rev Ciênc Farm Básica Apl. 2012;33(1):77-81.

5. Richardson K, Bennett K, Kenny RA. Polypharmacy including falls risk-increasing medications and subsequent falls in communitydwelling middle-aged and older adults. Age Ageing. 2015;44(1):90-6.

6. Martin P, Tamblyn R, Ahmed S, Tannenbaum C. An educational intervention to reduce the use of potentially inappropriate medications among older adults (EMPOWER study): protocol for a cluster randomized trial. Trials. 2013;14:1-17.

7. Cruz DT, Ribeiro LC, Vieira MT, Teixeira MTB, Bastos RR, Leite ICG. Prevalência de quedas e fatores associados em idosos. Rev Saúde Pública 2012;46(1):138-46. should also be highlighted, such as the fact that it was performed with elderly people living in the community, and so is less prone to selection bias than studies conducted in selected populations ${ }^{11}$.

\section{CONCLUSION}

The prevalence of the chronic use of benzodiazepines in the elderly was considered high, and similar to findings in literature. The use of benzodiazepines was associated with mental and behavioral disorders, polypharmacy and medical consultations. Prescription in the elderly, as well as prolonged use, should be evaluated with caution, considering the physiological changes among this population and the adverse effects of the medications.
8. Rahman MM, Davis DN. Addressing the class imbalance problem in medical datasets. Int J Marchine Learn Comput. 2013;3(2):224-8.

9. Bertolucci PHF, Brucki SMD, Campacci SR, Juliano Y. O Mini-Exame do Estado Mental em uma população geral: impacto da escolaridade. Arq Neuropsiquiatr. 1994;52(1):1-7.

10. Minas Gerais, Secretaria de Estado de Saúde. Manual do prontuário de saúde da família. Belo Horizonte: SES/MG; 2008.

11. Alvarenga JM, Loyola Filho AI, Firmo JOA, LimaCosta MF, Uchoa E. A population based study on health conditions associated with the use of benzodiazepines among older adults (The Bambuí Health and Aging Study). Cad Saúde Pública. 2009;25(3):605-12.

12. Jorm AF, Grayson D, Creasey H, Waite L, Broe GA. Long-term benzodiazepine use by elderly people living in the community. Aust N Z J Public Health. 2000;24(1):7-10.

13. Cunha CDA, Souza MCC, Cattanio GAA, Iahnn SR, Lima RC. Benzodiazepine use and associated factors in elderly in the city of Dourados, MS, Brazil. J Bras Psiquiatr. 2015;64(3):207-12.

14. Noia AS, Secoli SR, Duarte YAO, Lebrão ML, Lieber NSR. Fatores associados ao uso de psicotrópicos por idosos residentes no Município de São Paulo. Rev Esc Enferm USP. 2012;46(N. Esp):38-43. 
15. Fabrício-Wehbe SCC, Schiaveto FV, Vendrusculo TRP, Haas VJ, Dantas RAS, Rodrigues RAP. Crosscultural adaptation and validity of the "Edmonton Frail Scale - EFS" in a Brazilian elderly sample. Rev Latinoam Enferm. 2009;17(6):1043-9.

16. Lawton MP, Brody EM. Assessment of older people: self-maintaining and instrumental activities of daily living. Gerontologist. 1969;9(3):179-86.

17. Lowe B, Wahl I, Rose M, Spitzer C, Glaesmer H, Wingenfeld $\mathrm{K}$, et al. A 4-item measure of depression and anxiety: Validation and standardization of the Patient Health Questionnaire-4 (PHQ-4) in the general population. J Affect Disord. 2010;122(12):86-95.

18. Gnjidic D, Hilmer SN, Blyth FM, Naganathan V, Waite L, Seibel MJ, et al. Polypharmacy cutoff and outcomes: five or more medicines were used to identify community-dwelling older men at risk of different adverse outcomes. J Clin Epidemiol. 2012;65(9):989-95.

19. Brunton LL, Chabnert BA, Knollmann BC. Goodman \& Gilman: as bases farmacológicas da terapêutica. $12^{\mathrm{a}}$ ed. Rio de Janeiro: McGraw-Hill; 2012.

20. Zandstra SM, Furer JW, Van de Lisdonk EH, Van't Hof M, Bor JHJ, Van Weel C, et al. Different study criteria affect the prevalence of benzodiazepine use. Soc Psychiatr Psychiatr Epidemiol. 2002;37(3):139-44.

21. Préville M, Bossé C, Vasiliadis H, Voyer P, Laurier C, Berbiche D, et al. Correlates of potentially inappropriate prescriptions of Benzodiazepines among older adults: results from the ESA Study. Can J Aging. 2012;31(3):313-22.

22. Auchewski L, Andreatini R, Galduróz JCF, Lacerda RB. Avaliação da orientação médica sobre os efeitos colaterais de benzodiazepínicos. Rev Bras Psiquiatr. 2004;26(1):24-31.

23. Howard P, Twycross R, Shister J, Mihalyo M, Wilcock A. Benzodiazepines. J Pain Symptom Manage. 2014;47(5):955-64.
24. American Geriatrics Society. Beers Criteria Update Expert Panel. American Geriatrics Society 2015 updated Beers Criteria for potentially inappropriate medication use in older adults. J Am Geriatr Soc. 2015;63(11):2227-46.

25. O'mahony D, O'sullivan D, Byrne S, O'connor MN, Ryan C, Gallagher P. STOPP/START criteria for potentially inappropriate prescribing in older people: version 2. Age Ageing. 2015;44(2):213-8.

26. Van Strien AM, Koek HL, Van Marum RJ, EmmelotVonk MH. Psychotropic medications, including short acting benzodiazepines, strongly increase the frequency of falls in elderly. Maturitas 2013;74(4):357-62.

27. Billioti De Gage S, Pariente A, Bégaud B. Is there really a link between benzodiazepine use and the risk of dementia? Expert Opin Drug Saf. 2015;14(5):733-47.

28. Mendonça RT, Carvalho ACD, Vieira EM, Adorno RCF. Medicalização de mulheres idosas e interação com consumo de calmantes. Saúde Soc. 2008;17(2):95-106.

29. Alvarenga JM, Loyola Filho AI, GiacominKC, Uchoa E, Firmo JOA. Uso de benzodiazepínicos entre idosos: o alívio de "jogar água no fogo", não pensar e dormir. Rev Bras Geriatr Gerontol. 2015;18(2):249-58.

30. Santos TRA, Lima DM, Nakatani AYK, Pereira LV, Leal GS, Amaral RG. Consumo de medicamentos por idosos, Goiânia, Brasil. Rev Saúde Pública. 2013;47(1):94-103.

31. Carvalho MFC, Romano-Lieber NS, BergstenMendes G, Secoli SR, Ribeiro E, Lebrão ML, et al. Polifarmácia entre idosos do município de São Paulo Estudo SABE. Rev Bras Epidemiol. 2012;15(4):817-27.

32. Alvarenga JM, Giacomin KC, Loyola Filho AI, Uchoa E, Firmo JOA. Uso crônico de benzodiazepínicos entre idosos. Rev Saúde Pública. 2014;48(6):866-72.

33. Hood SD, Norman A, Hince DA, Melichar JK, Hulse GK. Benzodiazepine dependence and its treatment with low dose flumazenil. Br J Clin Pharmacol. 2012;77(2):285-94.

34. Tannenbaum C. Inappropriate benzodiazepine use in elderly patients and its reduction. J Psychiatry Neurosci. 2015;40(3):27-8. 